\title{
LOST: The Search For One's Self (A Rhythm-based Application that Promotes Awareness on Depression)
}

\author{
Jeff Rodiel Alcasid, Mario Ryan Aljama, Mikki Orcel Diaz, Siao Ming Beninsig, John Heland \\ Jasper Ortega ${ }^{+}$, and Maria Rona Perez \\ ${ }^{1}$ FEU Institute of Technology, Philippines
}

\begin{abstract}
With the fast-paced growth of technology in our generation today, a lot of different applications has been developed in order to make people's lives more convenient and comfortable. However, due to the people's attachment to these technology, they have grown more and more sensitive with what they read from the internet (especially social media) — this in return takes toll on their mental health capabilities and provides problems for them and their families. This study aims to promote the presence of a mental health issue that has been frequently discussed by a lot of people through the years - this disorder is known to be depression. The researchers' aim in this study is to develop a game that can aid people in understanding how depression affects the character through the said game's story — and help alleviate some possible factors that saddens or disrupts the player's mind from the gameplay and music. One of the main elements from this study is that interviews from psychologists, psychiatrists, and guidance counselors would be conducted and analyzed in order to know the possible problems that the target audience of the project may or may not face in their own lives - the researchers would then conduct a survey accompanied with the Patient Health Questionnaire (PHQ-8) in order to test the game's effectiveness and enjoyment. Based from the overall results of the study, the researchers were able to analyze the gathered PHQ-8 survey and has successfully rejected their null hypothesis — which means that the project has an effect on decreasing the severity of depression of the players. Overall, the researchers were able to satisfy their objectives which makes the project a step closer in developing an application that can be positively used for both entertainment and depression awareness in the future.
\end{abstract}

Keywords: Depression; Rhythm ; Video Game; Puzzle; 3D

\section{Introduction}

Technology has been a major part of our lives today. From phone applications to huge mechanical contraptions - everything was invented by humans for a the purpose of changing our lives to become better and more convenient. These advancements in technology has increased the success of our medical treatments, created more reliability on effective communication, reinforced a faster trade of stocks, etc. - and as most of the people all know, one of the major industries that benefits from the rapid advancement of technology is the Entertainment Industry.

Nowadays, teenagers, especially college students, are faced with a lot of issues and pressure from their families, friends, and especially the internet - they are exposed to the successes of other people from social media, making them re-assess themselves on who they are compared to the successful ones. Making them suffer anxiety or depression, causing them to have negative thoughts or have thoughts of committing suicide.

Video games, on the other hand, has been developing ways to help people relieve mental tension and stress by providing them various scenarios where they are given the freedom to make their own decisions by thinking outside of the box and let them reach certain achievements in the game. Although there is still a debate between the relation of video games and mental health, there are already a handful of articles and studies that leans to the notion that video games has an impact to a person's mental health.

The researchers have made this game in order to help people be entertained while promoting awareness on the issue of depression through the game. The game would offer a unique storyline as well as unique music and art style that will help the strengthen the player's gameplay experience.

\footnotetext{
+ Corresponding author. Tel.: (02) 82818888

E-mail address: jcortega@feutech.edu.ph.
} 


\subsection{Purpose and Description}

LOST: The Search for One's Self is a rhythm role-playing puzzle game for the PC with stylized-graphics and unique music where the player help Coraline fight against nightmares and get her memories back. The game has four different stages, including the tutorial stage. It would feature a rhythm based combat for the player to properly execute in order for them to beat the boss in the specific stage. Each boss will have unique attack patterns, giving the player different beats to follow - making the mechanics harder to perfect. The player will be given the chance to pick her instrument to fight against bosses. The game will feature three different instruments, the Piano, the Violin, and the Flute. Although there will be differences in instruments, the game would still have one consistent music all throughout the game. The game will also feature a level randomization system so that it will increase the replayability and competition for players. The purpose of this project is to promote awareness on how some factors of depression can affect the way of life of a person through the portrayal of letting the player play of a main character who is suffering from depression. The researchers seek to emphasize on the game's purpose by developing a game for their client, Anino Playlabs under the supervision of Paolo Miguel Abila.

\section{Related Literature and Studies}

\subsection{Mental Health}

Post-traumatic Cognition comes into three types - namely, negative cognitions about the world, negative cognitions about the self, and self-blame. One way to relieve these traumas is through the concept of cognitive processing therapy, where-in people teach the patients to have a more realistic and accurate evaluation about their problems. (Mordeno, Nalipat, \& Saavedra, 2018). [1]

Lopez (Interview, 2020) stated that the top 3 usual mental health issues that college students face nowadays are Depression, Anxiety, and Trauma respectively - it is usually triggered from the pressure from expectations in a social aspect such as friends and families. Treatment, on the other hand, depends on the needs of the student - Cognitive Behaviour Theraphy (CBT) is a common tool that can help the students to open up and change their perception on the events or people in their life. [2]

\subsection{Music and Puzzles}

Borchard (2017) stated that music has been used to heal the body and soul through the ages - thousands of soldiers from World War II that has developed post-traumatic stress disorder has been visited by musicians to ease emotional trauma. It was noted by the nurses and doctors that the patients had a positive response and it helped them forget the trauma they had from the war. The American Music Therapy Association has listed studies that support the benefits of music therapy - out of these studies, it was found that music therapy can decrease anxiety, increase motivation, enhance interpersonal relationships, reduce muscle tension, etc. [3]

Accordin to Waterman (2018), puzzles in games usually revolve on at least one specific mechanic. For example, putting a box on a pressure plate can already be a puzzle - this will mainly revolve on how the developers would create a challenge to the puzzle by making the player have a hard time transporting the box to the pressure plate itself. This can be thoroughly attained by adding obstacles and a few unique mechanics to the puzzle itself - although adding obstacles can make it difficult for the players, it should be accompanied with the proper feedback, clues, and visual aids for it to not become impossible for the players to solve. [4]

One of the reasons for a teenager to commit suicide is the thought of being alone. Some may feel that they are not being cared by their parents, or bullied from school - these factors contribute to a person's way of thinking, creating negative thoughts that they cannot control. On the other hand, music can help alleviate negative thoughts and help some people escape their own reality - while puzzles can help people change their perspective on the problem. (Villaranda [Interview], 2020) [5]

Music can help distract oneself from over-thinking while puzzles can help give people confidence when solving it, such as a simple gesture of fixing the bed can give a sense of accomplishment to a person However, giving a purpose to why the player must solve puzzles would be more beneficial than designing a puzzle just for gameplay. (Lopez [Interview], 2020). [2]

\subsection{Video Games}


Mcgonigal (2015), has stated that when people play video games, the two regions of the brain are being simulated at the same time - even if it is as simple as solving a simple puzzle, scoring points, finding hidden objects, etc. it creates a goal-oriented personality in making the player more motivated and determined when anticipating success. [6]

As stated in the article, it was found out that the more that the video games' difficulty increase, the more players are challenged to solve more problems, the less likely they give up because they would want to know the reward for finishing the problem. For emotional benefits, the article has stated that most children regulate their fear and anger through playing video games - mainly because they see excitement in playing them while forgetting the negative emotions that they had. (Gray, 2018) [7]

According to Judge (2018), there has been research stating that video games can cause emotional changes in players. Games such as Life is Strange has dealt some of the difficult themes like suicide and gave proper advice on how to tackle the issue. Although the correlation of video games and mental health is still in debate nowadays, most of the evidence right now leans to the notion that video games has an impact to mental health. [8]

According to Parcon (2017), children who were more engaged in role-playing or were involved in conversing with another person, has a thorough enhancement for cognitive perspective. As for attachment, there is also an association between anxiety and emotional contagion - anxiety is often depicted for the worry of abandonment which leads people to be more affected by the emotions of others. [9]

\subsection{Mental Health}

Bodycombe (2017) stated that depression is a mental health issue that is affecting a lot of people every year, it has also been a significant problem for most college students. Through the years, it has been looked into by experts and studies that video games can be used as a treatment to some psychological conditions namely, to reduce aggression, address phobias, increase emotional regulation, complement other therapeutic modality, and educate patients with their illnesses. [10]

According to Bernardo, King, \& Datu (2018), financial stress has negatively affected a student's wellbeing, family relations, peer relations, and any external locus of hope dimension. Without the appropriate locus of hope, emotional awareness and self-efficacy can continue to lessen the chances of making a person have a happy, meaningful, and successful life. [11]

Although there are a lot of people who experience a traumatic event develop a post traumatic stress disorder, it is quite uncommon for these survivors to suffer from serious symptoms. However, some of the minor symptoms of post traumatic stress disorder include nightmares, flashbacks, difficulty concentrating, guilt, etc. It was found out that reconstructing a trauma while engaging in various activities can have an impact to people and help them heal from their traumatic experiences. (Rose, 2019) [12]

\subsection{Patient Health Questionnaire (PHQ-8 \& PHQ-9)}

The Patient Health Questionnaire (PHQ-9 \& PHQ-2) offer concise, self-administered tools for assessing depression - they are used in many studies, mostly primary care settings, as well as people who have physically disabling conditions. The Patient Health Questionnaire (PHQ-9 \& PHQ-2) incorporate the Diagnostic and Statistical Manual of Mental Disorders (DSM-IV)'s criteria and summarized it to make a brief self-report instrument that can be used for monitoring, screening, and diagnosis purposes. (American Psychological Association, 2020) [13]

A research by Lisicka et al. (2017) provided evidence for the reliability of the PHQ-9, stating that the PHQ-9 is a useful assessment tool in measuring the severity of depression - However, they have also stated that the PHQ-9 questionnaire is not often reliable to use for diagnostic purposes. [14]

\section{Methodology}

This chapter discusses the methodology used by the researchers in developing their capstone project. The first part of the chapter tackled on the different feasibility of the proposal and project, in order to know how the group should mobilize and see whether the project is doable or not. This chapter also includes the project's design and architecture - consisting of the game's overview, story, character designs, gameplay, level designs, 
and other necessary charts that were used to establish the foundation of the game. Lastly, this chapter discusses the data gathering process using the Likert Scale and FURPS methodology while analyzing the study through the use of mean, Cronbach's Alpha, and the paired t-test from the conducted Patient Health Questionnaire (PHQ-8).

\subsection{Project Design}

LOST is a rhythm role-playing game for the PC with stylized-graphics and unique music where the player helps Coraline fight against nightmares and get her memory back. The game would feature a rhythm based combat for the player to beat the boss in the specific stage. Each boss will have unique attack pattern and different stage beats to follow - making the mechanics harder to perfect. The player will use instruments to fight against bosses. The game will feature three different instruments, the Piano, a Violin, and a Flute. Although there will be differences in instruments, the beats in the music will be the same. The game will also feature a puzzle randomization so that it will increase the replayability for players.

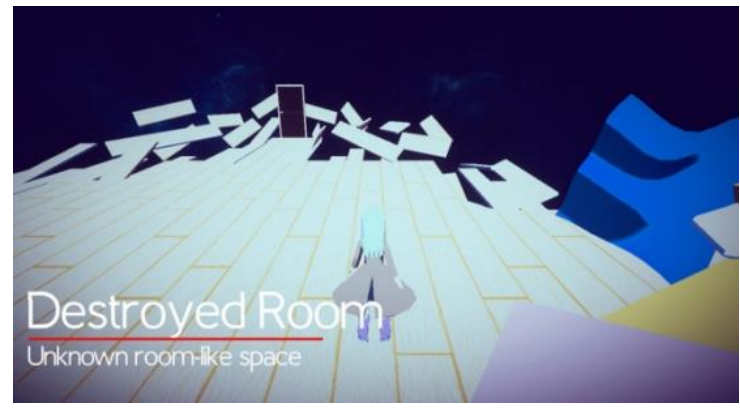

Fig. 1: Hub Area

In figure 1, this scene is often seen by the player when they first start the game, finish every boss, and this evolves throughout the whole gameplay of the player. This specific stage revolves around the main character's bedroom where she has a faint memory with.

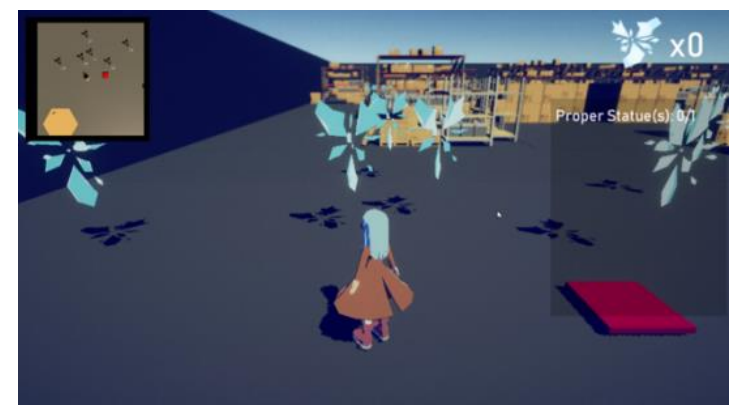

Fig. 2: Core Puzzle Gameplay

The figure above shows the main gameplay mechanics of the puzzle for the game - the player is met with a tutorial on what they should be doing in order to be able to accomplish the said stage and be able to go to the boss stage. In the figure, the player is tasked to put the statues back to their original positions and collect memory fragments that will serve as an aid for the player during the boss battles.

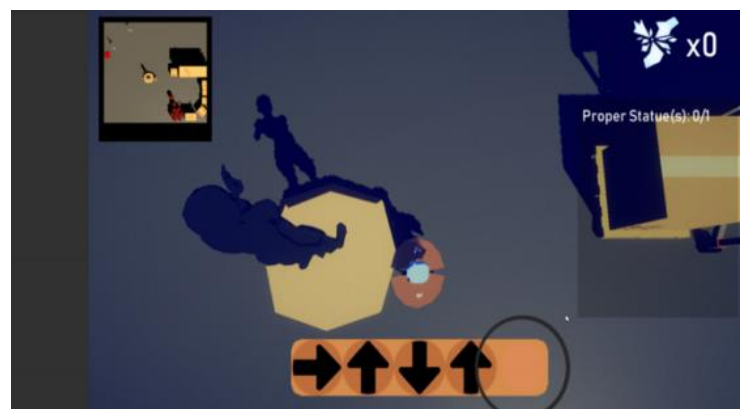

Fig. 3: Game Rhythm Mechanics

In figure 3, this shows the main rhythm mechanics that game is incorporating for both puzzle and boss 
stages. In this figure, the player is prompted to input certain arrow keys and listen to the stage's music and press a certain button on the beat in order for the game to accept their input.

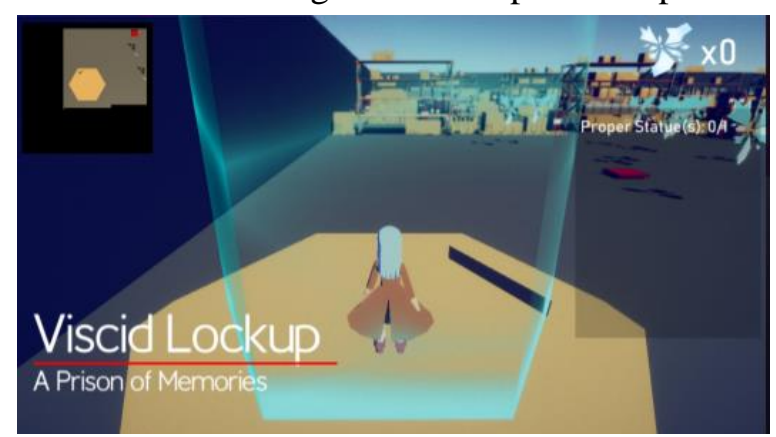

Fig. 4: Level 1 Puzzle

In this figure, it shows the main entrance of the first level puzzle stage.

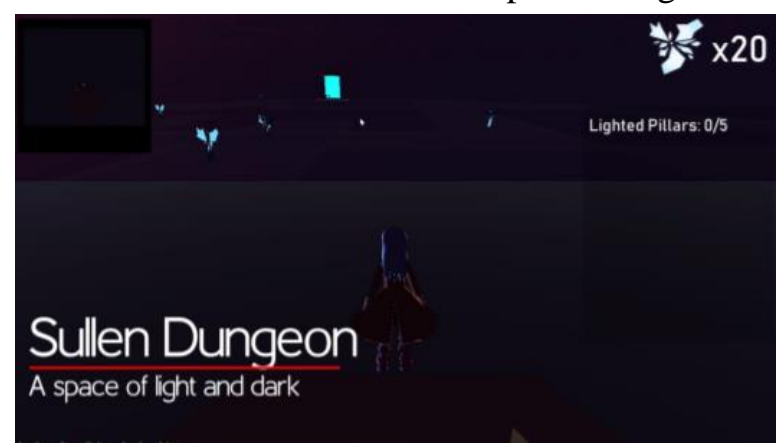

Fig. 5: Level 2 Puzzle

In figure 5 , it shows the main entrance of the second level puzzle stage.

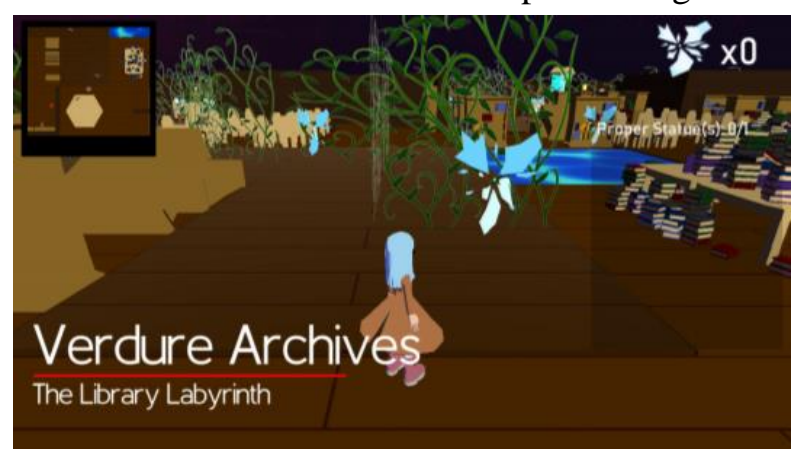

Fig. 6: Level 3 Puzzle

In figure 6, it shows the main entrance of the second level puzzle stage.

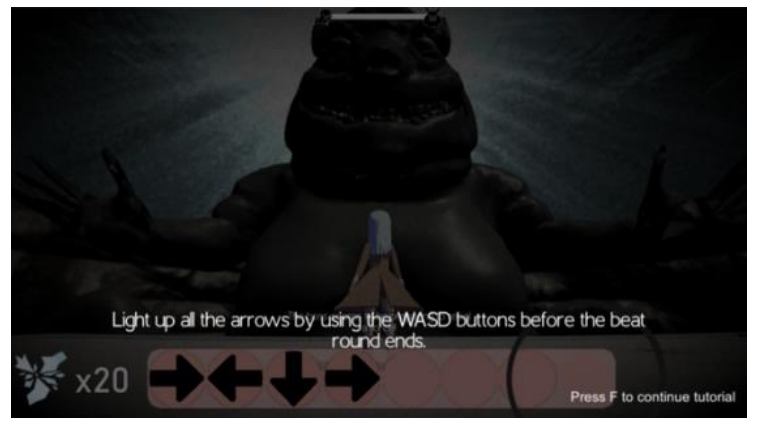

Fig. 7: Boss Mechanics

In the figure above, it displays the tutorial for the boss level for stage 1. Like the puzzle mechanics, the boss is battled using the arrow key inputs that the player feedbacks to the game while following the level's music. Each boss is related to a certain trauma of the main character, in accordance to what the researchers 
have analyzed through the interviews they have conducted during the planning phase of the project.

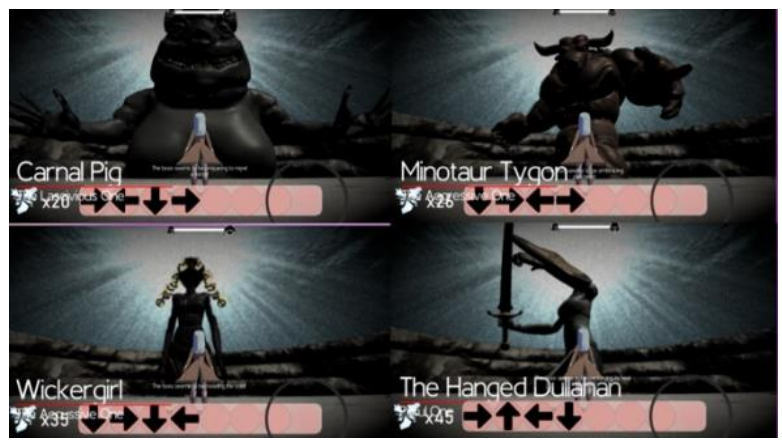

Fig. 8: All Boss 3D Models and Stage

In figure 8 , it shows the all of the boss models and their corresponding stages from the game.

\subsection{Project Architecture}

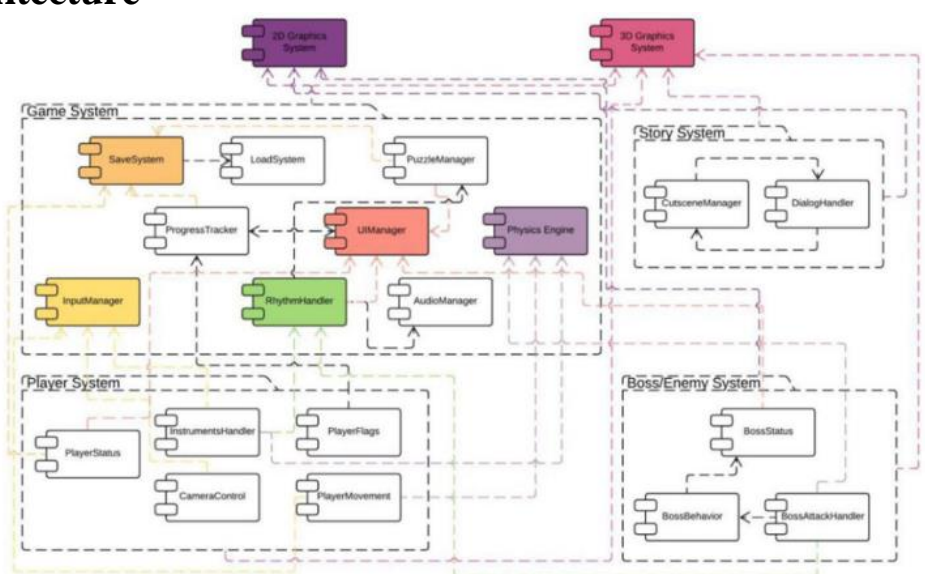

Fig. 9: Component Based Architecture

LOST is a rhythm role-playing game for the PC with stylized-graphics and unique music where the player helps Coraline fight against nightmares and get her memory back. The game would feature a rhythm based combat for the player to beat the boss in the specific stage. Each boss will have unique attack pattern and different stage beats to follow - making the mechanics harder to perfect. The player will use instruments to fight against bosses. The game will feature three different instruments, the Piano, a Violin, and a Flute. Although there will be differences in instruments, the beats in the music will be the same. The game will also feature a puzzle randomization so that it will increase the replayability for players.

\subsection{Data Gathering Procedure}

This project aims to develop a game that is catered to help teenagers alleviate the mental stress of the player or serve as an application that promotes mental health awareness to its players. The researchers would conduct interviews from professionals - such as psychologists, psychiatrists, guidance counselor, etc. Each of the interview transcripts would be thoroughly analyzed by the researchers to fit certain elements to cater for the proponent's goal. The interview analysis would help the researchers know what specific traumas are the appropriate things to incorporate to be part of the game. The researchers would also utilize surveys as a data collection method from the players of the project. The survey would be ideal for a large number of respondents, and would help them evaluate the game's effectiveness - and let them also know if they have attained the objectives of the research. However, due to the COVID-19 pandemic - there where changes with the presentation of the game. Therefore, it affected the gathering procedure from the surveys and would reduce the number of respondents due to the scheduling of the open house

\subsection{Testing}

The researchers would use three three types of testing - Namely, Alpha Testing Beta Testing, and User Acceptance Testing - these test would help the researchers know the overall progress of the game before it 
is released to the public.The researchers would first conduct Alpha Testing of the game, in order for them to be able to see if the incorporated ideas are appropriate for the audience - it would also help the researchers to find possible bugs and issues in the game. The next stage that the researchers would follow will be the Beta Testing, this test will be used to know the player's satisfaction for the overall progression of the project - this will mainly be done after the alpha testing of the stage where the game is already thoroughly troubleshooted and patched. Through this, the researchers will be able to know the player's reaction and experience. Lastly, the researchers will use the User Acceptance Testing to know if the game has accomplished the necessary requirements given by the client. This test will only be performed as the final phase of the software development before it is released to the users to play.

\subsection{Statistical Treatment}

The researchers will use the Patient Health Questionnaire (PHQ-8) in order to find the players' psychological state before and after the game - and will be analyzed using the Paired T-test to determine the effectiveness of the game's purpose. The researchers will use a Likert Scale to rate the players experience on the game ( 1 - strongly disagree, 2 - disagree, 3 - neutral, 4 - agree, 5 - strongly agree), and use Cronbach's Alpha to test the overall consistency of the implementation of the Likert Scale. and architecture - consisting of the game's overview, story, character designs, gameplay, level designs, and other necessary charts that were used to establish the foundation of the game. Lastly, this section also discusses the data gathering process using the Likert Scale and FURPS methodology while analyzing the study through the use of mean and the paired ttest from the conducted Patient Health Questionnaire (PHQ-8).

Table 1: Likert Scale Rating and Interpretation

\begin{tabular}{|c|c|}
\hline Rate / Score & Interpretation \\
\hline $4.5-5.0$ & Strongly Agree \\
\hline $3.5-4.49$ & Agree \\
\hline $2.5-3.49$ & Neutral \\
\hline $1.5-2.49$ & Disagree \\
\hline $0.0-1.49$ & Strongly Disagree \\
\hline
\end{tabular}

The Likert Scale is used to gather respondents opinion about the gameplay, music, user interface, and 3D assets of the game - this is to determine whether the researchers were able to make a game suitable for their course requirements and for them to know if their game is decent for a small team of developers. The FURPS methodology is used to know the game's functionality, usability, reliability, performance, and sustainability - this methodology is used together with the Likert Scale in order to let the researchers know if their website is well received by the respondents and they think that the website is suitable for a thesis project. Lastly, the Patient Health Questionnaire (PHQ-8) is conducted before and after the play testing of the game - this is for the researchers to test whether their project has potential to serve as an aid for people who suffer from depression. The questionnaire is analyzed through the use of the Paired T-Test in order to test whether the researchers should reject the null hypothesis or not.

\subsection{Used Formulas}

$$
\begin{aligned}
& \bar{x}=\frac{\sum x}{n} \\
& \text { where } \bar{x} \quad=\text { Arithmetic Mean of the category } \\
& \sum x=\text { Sum of the scores of a category } \\
& \mathrm{n}=\quad \text { number of questions in the category }
\end{aligned}
$$

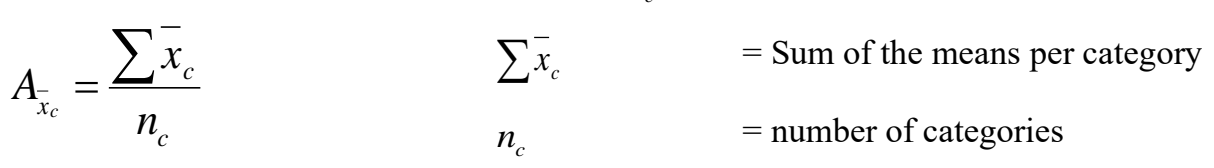




$\begin{array}{lll}t=\frac{\bar{x}_{s}}{\left(S_{d} / \sqrt{n_{s}}\right)} & \text { where } \mathrm{t} & =\text { Paired T-Test Result } \\ & \bar{x}_{s} & =\text { Sample Mean Difference } \\ \mathrm{Sd} & =\text { Standard Deviation of Difference } \\ \mathrm{ns} & =\text { Total Number of Sample } \\ \alpha=\frac{K}{K-1} \times\left(1-\frac{\sum_{i=0}^{K} S_{i}^{2}}{S_{t}^{2}}\right) & \text { where } \alpha & =\text { Cronbach's Alpha } \\ & \mathrm{K} & =\text { Total Number of Questions } \\ & \sum_{i=0}^{K} S_{i}^{2} & =\text { Sum of the Item Variances } \\ S_{t}^{2} & =\text { Variance of Total Scores }\end{array}$

\section{Results and Discussion}

The researchers has conducted a convenient sampling using a survey with thirty-five (35) survey questions accompanied with an eight (8) question Patient Health Questionnaire (PHQ-8). The survey questionnaire questionnaire consists of 20 questions concerning about the game's gameplay (5), user interface (5), 3D assets and models (5), and the game's sound design (5) - while the remaining 15 is centered on the game's website which consists of the web's functionality (3), usability (3), reliability (3), performance (3),. and supportability (3). The Likert scale will be used to analyze the gathered data from the survey, while the Cronbach's alpha is used to check the overall consistency of the survey. All of these were computed using the default computation of Microsoft Excel.

Table 2: Mean Summary for Game Evaluation

\begin{tabular}{|c|c|c|}
\hline Criteria & Mean & Verbal Interpretation \\
\hline Gameplay & 3.55 & Agree \\
\hline User Interface & 4.08 & Agree \\
\hline 3D Assets and Models & 3.75 & Agree \\
\hline Sound Design & 4.04 & Agree \\
\hline TOTAL & 3.86 & Agree \\
\hline
\end{tabular}

The table shows that the the respondents agree with the current status of development for the game. With the said overall mean, the proponents have found that the game is on the right track on its developmental stage.

Table 3: Mean Summary for Game Evaluation

\begin{tabular}{|c|c|c|}
\hline Website Criteria & Mean & Verbal Interpretation \\
\hline Functionality & 4.62 & Strongly Agree \\
\hline Usability & 4.62 & Strongly Agree \\
\hline Reliability & 4.65 & Strongly Agree \\
\hline Performance & 4.63 & Strongly Agree \\
\hline Sustainability & 3.92 & Agree \\
\hline Total & 4.49 & Agree \\
\hline
\end{tabular}

Table 3 shows that the respondents agree with the current status of game's website. With the said overall mean, the proponents have found that the overall functionality and use of the website is proper and is adequate for the viewers.

Table 4: Paired T-Test (Post Evaluation)

\begin{tabular}{|c|c|c|c|c|c|}
\hline & N & $\begin{array}{c}\text { PHQ-8 Mean } \\
\text { Difference }\end{array}$ & $\begin{array}{c}\text { Standard } \\
\text { Deviation of } \\
\text { Difference }\end{array}$ & $\begin{array}{c}\text { Calculated Paired } \\
\text { T-Test }\end{array}$ & $\begin{array}{c}\text { Critical Paired T- } \\
\text { Test }\end{array}$ \\
\hline $\begin{array}{c}\text { Patient } \\
\text { Health } \\
\text { Questionnaire } \\
\text { (PHQ-8) }\end{array}$ & 15 & 3.13 & 3.94 & 3.08 & 2.15 \\
\hline
\end{tabular}


The proponents conducted the PHQ-8 survey to know if the game's purpose improves once the game has been completed with more stages and bosses - and based from the results of the survey, it has shown that the overall general Paired T-Test is higher than the previous conducted survey, garnering a value of 3.13 which is higher than the tabulated value of 2.15 shows that the proponents have successfully rejected the null hypothesis, which therefore states that the project has a significant effect on decreasing the severity of depression of the players. With a low P-Value of 0.01 or $1 \%$ this shows that the study has a strong foundation to reject the null hypothesis.

\section{Conclusion}

Based on the overall results found in section 4 , the researchers were able to evaluate the following objectives that were needed for the project.

\subsection{Objectives}

5.1.1 Gather data and information about mental illnesses from the interviews with psychiatrists, psychologists, guidance counselors, etc.

The researchers were able to collect information on mental illnesses from psychologists, psychiatrists, and guidance counselors. All of their said input greatly helped the researchers decide on what elements should they incorporate and avoid in the game.

5.1.2 Analyze the factors, design puzzles, level design, 3D assets, and boss behaviors for the four levels of the game.

The researchers surveyed the game's gameplay, user interface, 3D assets \& models, and the sound design. Each had a mean of 3.55, 4.08, 3.75, and 4.04 respectively, resulting in an overall mean of 3.86. This meant that the project had a positive response from the respondents and was appropriate for their playing experience.

\subsubsection{Develop a website that will display information about the developer, client, and game.}

The researchers' survey for the website also garnered a decent average, having a total mean of 4.49. This illustrated that the researchers properly developed a website with features such as updates, information, contact, support, etc.

5.1.4 Evaluate the game's quality, through the use of surveys and the Patient Health Questionnaire (PHQ-8) in open houses, based on its gameplay, animation, the overall feel, and the game's effectiveness in decreasing the severity of depression.

The researchers' project resulted from the summary of the Patient Health Questionnaire (PHQ-8) showed that the severity of depression has decreased after the gameplay. The Paired T-Test value had a value of 3.08 which was lower than the tabulated Paired T-Test value of 2.15 . This implied that the researchers had successfully rejected their null hypothesis and found that the game had an effect of decreasing the severity of depression.

The researchers, therefore, concluded that they have satisfied their overall objectives of the project. The overall mean of the gameplay summary during the beta test was in a satisfactory range, and they thought that the overall purpose of the game had been fulfilled. Moreover, since the calculated Paired T-Test value is higher than the tabulated Paired T-Test value, the researchers would have to accept their alternative hypothesis which stated that the game had a significant effect on decreasing the severity of depression of the player.

\section{Recommendations}

The researchers recommend going for a different approach for the data gathering process and statistical treatment - this can be done by changing to a different survey or statistical treatment rather than the conducted Patient Health Questionnaire (PHQ-8), and the Paired T-Test to know whether the game has an impact or not. They also suggest to implement this kind of approach in order for future researchers to know if their game has a significant effect on the players or none. However, having a fully functional game, one can easily implement the survey on the start of the game so that the respondent's would not feel that they are answering a survey while sending it's results on the website — due to the pandemic, the developers were not able to continue on 
this plan because of the changes on the open house instructions. Future researchers can also continue using the survey instrument and statistical treatment to know the overall consistency of the done statistical treatment however, they should consider to increase the possible number of respondents to have more credibility and reliability.

The researchers would also want future game developers to test and try other software in developing a game - various 3D modeller software may help improve with the overall development and quality of the assets based on the preference of the group's 3D artist. It would also be great to explore using a different medium such as a console or mobile, this project is limited to the PC that is why it can only target specific audiences who play on their personal computers only.

\section{Acknowledgements}

The researchers would like to thank FEU Institute of Technology for giving the opportunity to do the research project and be given an opportunity to publish it. The researchers extend their sincerest gratitude to their Mentor, Mr. John Heland Jasper Ortega, for sharing his knowledge, time, and expertise in this project. Without his help, this researchers would not have any idea if they are on the right track in accomplishing a well-written and direct research. The researchers would like to thank their course adviser Dr. Maria Rona Perez, for giving her continuous support in teaching the researchers the necessary information needed for the thesis and for her long patience in signing all the necessary letters in conducting interviews to psychologist, psychiatrists, and guidance counselors. The researchers would like to extend their sincerest gratitude to the panels, for providing their time and experience in giving critical feedback and suggestions to make the game improve, leading the group to follow the right path, and understanding the hardships the researchers face during the pandemic. The researchers would like to give their appreciation to the psychologists, psychiatrists, and guidance counselors who contributed their personal expertise and experiences in giving the necessary information to clear out all the ambiguity that the researchers face in mental health, and providing them the appropriate approaches to the said issue. Lastly, the researchers would like to thank the frontliners who risked their lives to fight against COVID-19 virus.

\section{References}

[1] Mordeno, I.G., Nalipay, M.J., Saavedra, R.L. (2015). Cognitive Processiong, PSTD Symptoms, and the Mediating role of Posttraumatic Cognitions. Philippine Journal of Psychology, 48(2), pp. 3-26. Retrieved from pap.org.ph/sites/default/files/pdf/PJP1502_Final_1Nalipay_et_al.pdf

[2] Lopez, J. (2020). An interview with Ms. Jomelyn Lopez [Interview]. (Appendix A). Far Eastern University. Sampaloc, Manila.

[3] Borchard, T. (2017). How music therapy can relieve depression. Retrieved from https://www.everydayhealth.com/columns/therese-borchard-sanity-break/music-therapy-to-relieve-depression/

[4] Waterman, J. (2018). Crafting better puzzles for roleplaying games. Retrieved from https://www.nerdolopedia.com/articles/2018/7/13/crafting-better-puzzles-for-roleplaying-games

[5] Villaranda, R. (2020). An interview with Mr. Ronald Villaranda [Interview]. FEU Institute of Technology. Sampaloc, Manila.

[6] Mcgonigal, J. (2015). How video games can teach your brain to fight depression. https://slate.com/technology/2015/11/how-video-games-can-teach-your-brain-to-fight-depression.html

[7] Gray. P. Ph.D. (2018). Benefits of play revealed in research on video gaming. Retrieved from https://www.psychologytoday.com/us/blog/freedom-learn/201803/benefits-play-revealed-in-research-videogaming

[8] Judge, A. (2018). Video games and mental health: 'Nobody's properly talking'. Retrieved from https://www.bbc.com/news/newsbeat-44662669

[9] Parcon, A.M. (2017)., Anxiety-Attachment, Avoidance-Attachment and gender as predictors of empathy. Philippine Journal of Psychology, 50(1), pp. 77-102. Retrieved from https://www.pap.org.ph/sites/default/files/upload/pjp2017-50-1-pp77-102-parcon-anxiety-attachment_avoidance- 
attachment_and_gender_as_predictors_of_empathy.pdf

[10] Bodycombe, J. (2017). Recommendations for developing video games to address depression among college students. (Unpublished Doctoral Thesis). University of Denver. Retrieved from https://digitalcommons.du.edu/cgi/viewcontent.cgi?article=1274\&context=capstone_masters

[11] Bernardo, A.B., Datu, J.A, King, R.B. (2018). Positive Psychology Research in the Philippines: An introduction. Philippine Journal of Psychology. vol. 2018, no.1, pp.21-32. https://doi.org/10.31710/pjp/0051.01.02

[12] Rose, L.H. (2019). The role of meaning making in expressive writing and adults with Post Traumatic Stress Disorder: A literature review. (Capstone Thesis). Lesley University. Retrieved from .https://digitalcommons.lesley.edu/expressive_theses/122

[13] American Psychological Association. (2020). Patient Health Questionnaire (PHQ-9 \& PHQ-2). Retrieved from https://www.apa.org/pi/about/publications/caregivers/practice-settings/assessment/tools/patient-health

[14] Lisicka, A., Richardson, T., Wrightman, M., Yeebo, M. (2017). Reliability and Score Ranges of the PHQ-9 and GAD-7 in a Primary and Secondary Care Mental Health Service. J. Psychosoc. Rehabil. Ment. Health 4, 237 240.. https://doi.org/10.1007/s40737-017-0090-0 